\title{
The Effectiveness of hrGFP Gene Reporter Role in Carp Fish (Cyprinus carpio) Transgenesis Process Based on Convocal Microscopy Analysis
}

\author{
Septi Anitasari ${ }^{1}$, Agus Soeprijanto ${ }^{2}$, Abd. Rahem Faqih ${ }^{2 *}$ \\ ${ }^{1}$ Master Program of Fisheries and Marine Sciences, Faculty of Fisheries and Marine Sciences, University of Brawijaya, \\ Malang, Indonesia \\ ${ }^{2}$ Faculty of Fisheries and Marine Sciences, University of Brawijaya, Malang, Indonesia
}

\begin{abstract}
Sperm cells can be used as a medium to insert foreign DNA into the egg. Electroporation humanized renilla reformis Green Fluorescent Protein (hrGFP) gene as a reporter gene is very important to know the effectiveness of gene transfer. Research is aimed to understand the effectiveness rate of hrGFP gene reporter to detect the successful gene transfer process based on the result of observation with convocal microscope over transgenic sperm level, embryo and larva of Carp Fish. Result of trans-genesis of hrGFP as sperm-mediated gene reporter must be accurately detected. Based on the result of observation with convocal microscope, it is shown that hrGFP enters the core level, indicates by $\mathrm{PI}$ pigmentation and thereby, hrGFP gene reporter can provide information about hrGFP fluorescence starting from sperm, embryo and larva of Carp Fish.
\end{abstract}

Keywords: Carp Fish, effectiveness, gene reporter, hrGFP, sperm fluorescence.

\section{INTRODUCTION}

One aspect that can be potentially exploited in the cultivated fisheries sector is the increase of growth rate of the fish itself. Transgenesis technology may be useful for this goal, especially electroporating method. This method is selected due to its practicality, effectiveness and efficiency. Besides, electroporating trans-genesis method can be combined with trans-genesis method of Sperm Mediated Gene Transfer (SGMT), where sperm is the transfer media. Sperm cell can be used as the media to transfer external DNA into ovum cell [1]. However, effectiveness rate of this combination must still be investigated. The examination over effectiveness and successful rates of such gene transfer needs a technique that can provide information about the successful gene transfer. For this interest, humanized renilla reformis Green Fluorescent Protein (hrGFP) is used as gene reporter.

The electroporating of GFP gene as gene reporter is very important to understand the effectiveness of gene transfer. The electroporating of sperm as gene transfer media has higher effectiveness than other method. Sperm as a vector carrying hrGFP gene is expected to be

\footnotetext{
* Correspondence author:

Abd. Rahem Faqih

Email : ar.faqih@ub.ac.id

Address : Faculty of Fisheries and Marine Sciences, University of Brawijaya, Jl. Veteran Malang, 65145
}

consistent until it reaches nucleus so that GFP can bring along information about the reliability of trans-genesis method [2].

This research was aimed to understand the effectiveness rate of GFP gene reporter to detect the successful of gene transfer process based on the result of observation with convocal microscope over transgenic sperm level, embryo and larva of Carp Fish. The determination of proper parameters in gene transfer process based on the electroporating of sperm may facilitate the development transgenic fish in quicker way. It may also be helpful to apply the information about gene transfer technique to the preparation of other transgenic fishes.

\section{MATERIALS AND METHODS}

The research was conducted at the Laboratory of Fish Breeding and Reproduction, Faculty of Fisheries and Marine Sciences, and the Central Laboratory of Biological Science, University of Brawijaya - Malang. It was conducted from December 2014 to March 2015. Materials needed in this research are: the prime of Carp Fish (Cyprinus carpio), sperm of Carp Fish, egg of Carp Fish Ovarium, physiological solution, hrGFP, hematoxylin eosin, toilet paper, cotton, alcohol $70 \%$, propidium lodide (PI), glycerin, nail dye, PBS solution, aluminum foil, and sterile aquades.

Equipments used in this research are: 1 set of Gene Pulser XcellTM kit of brand BIO-RAD comprising of electroporator machine, shock pod 
and cuvette; Convocal Microscope (Convocal Laser Scanning Microscope/CLSM) of brand Olympus Flouview Version 1.7a; Microscope Olympus BX 51 of Inverted Type; Binocular Microscope of Brand Olympus CX21; weight scale; ruler; Petri dish; plastic bowl; $5 \mathrm{ml}$ spud; section set; prime rearing batch; incubator set; plastic batch; fish net; napkin; blade; tray; micropipette; appendorf; blue tip; yellow tip; white tip; drop pipette; digital camera; glass object; cover glass; $\mathrm{pH}$ meter; DO meter; thermometer; and hand-tally counter haemocytometer.

\section{Procedure}

In this research, hrGFP concentration is examined on some parameter conditions of electroporating (pulsation) such as pulse voltage of $30 \mathrm{~V} . \mathrm{cm}^{-1}$, pulse length of $1 \mathrm{~ms}$ and pulse number of 4 times (Factor A). Treatment includes different concentrations of GFP (Factor B) such as 30 ng. $\mu \mathrm{L}^{-1}, 60$ ng. $\mu \mathrm{L}^{-1}$, and 90 ng. $\mu \mathrm{L}^{-1}$ (Table 1). This research was also conducted control (no treatment), and each treatment was repeated 3 times.

Table 1. Treatment of hrGFP

\begin{tabular}{llc}
\hline Treatment & \multicolumn{1}{c}{ Electroporation } & hrGFP $\left(\mathbf{n g} \cdot \boldsymbol{\mu \mathrm { L } ^ { - 1 }}\right.$ ) \\
\hline $\mathrm{A}_{1} B_{1}$ & electric field $30 \mathrm{~V} / \mathrm{Cm}^{-1}$ & 30 \\
$\mathrm{~A}_{1} B_{2}$ & pulse length $1 \mathrm{~ms}$ & 60 \\
$\mathrm{~A}_{1} B_{3}$ & pulse number 4 times & 90 \\
\hline
\end{tabular}

Initially, the prime is selected to obtain sperm and egg of Carp Fish Cyprinus carpio. The collected sperm is electroporated with Gene Pulser XcellTM Electroporation System Biorad by pouring $25 \mu \mathrm{L}$ sperm into cuvette $(0.2 \mathrm{~mm})$ of the electroporator and added with $8 \mu \mathrm{L}$ GFP. Gene construction that is used in this research is GFP gene with actine beta promoter of Medaka Fish at different concentrations, respectively 30,60, and $90 \mathrm{ng} \cdot \mathrm{LL}^{-1}$. The mix is then pulsed (electroporated) with voltage of $30 \mathrm{~V} . \mathrm{cm}^{-1}$, pulse length of $1 \mathrm{~ms}$, and number of pulse of $4 \mathrm{x}$. The electroporated sperm is added with $267 \mathrm{NaCl}$ Physiologic Solution (total solution becoming 300 $\mu \mathrm{L})$. Sperm is subtracted by $100 \mu \mathrm{L}$ for DNA analysis, $100 \mu \mathrm{L}$ for fertilization, $5 \mu \mathrm{L}$ for motility observation, $5 \mu \mathrm{L}$ for validity examination, $5 \mu \mathrm{L}$ for observation of GFP fluorescence, and the remaining is used as reserve.

Fertilization was conducted artificially. Sperm from electroporation was arranged into eggcontaining Petri dish. Water was added and the solution was mixed or stirred using chicken feather. Embryo was then collected and moved into incubator batch, and allowed until hatching.

The motility and viability of sperm observed with inverted microscope. Sperm density counted with hameocytometer and facilitated by sperm core pigmentation with $\mathrm{PI}$. hrGFP fluorescence of sperm, embryo and larva was observed by convocal microscope.

\section{RESULT AND DISCUSSION}

The Analysis of GFP Fluorescence on Sperm, Embryo and Larva

Result of observation on post-electroporating sperm based on convocal microscope has indicated that hrGFP can enter into the sperm cell. It is proved by green fluorescence of hrGFP in sperm cell as shown by convocal microscope (Fig. 1).

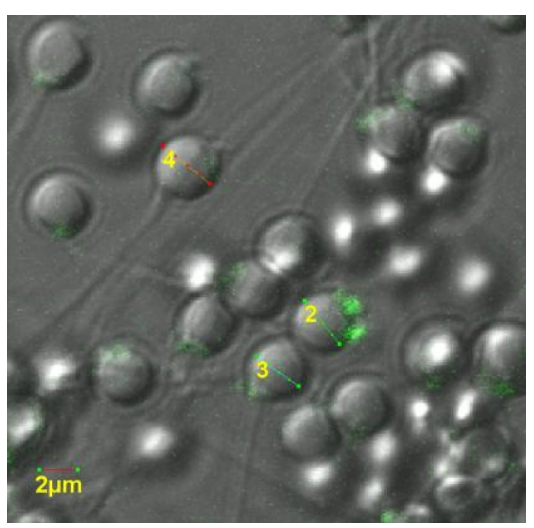

Figure 1. Fluorescence and interaction of hr GFP in Carp Fish sperm

Regarding to the result of observation by convocal microscope, it is shown that $57.6 \%$ electroporated sperm have changed into transgenic due to the infiltration of transferred hrGFP. Figure 1 also indicates that post-treated sperm is infiltrated by hrGFP and hrGFP links with sperm at sub-acrosom point, precisely at the head base of Carp Fish sperm. The interactive condition of sperm and GFP was supported by previous study where interaction between fish sperm and GFP based on the electroporation process over Catfish (Clarias spp) and Nilam Fish (Osteochillus haselti) has produced a linkage at head base part (sub-acrosom) [3].

Exogenous DNA adheres with the outside layer of spermatozoa [4]. Spermatozoa's exogenous DNA usually links to sub-acrosom part of sperm head [5]. Motile sperm have reported has more capacities to bind DNA and 30\% motile sperms can bring DNA along with them [6], that $84.8 \%$ DNA cling to head posterior area, less than 
$1 \%$ remain outside acrosom, around $2 \%$ stay in equatorial part, and around $12.7 \%$ DNA bind with posterior extremity of sperm head [7].

To understand the interaction of hrGFP with sperm cell after infiltration, PI pigmentation was given and observed under convocal microscope. The finding showed that all sperms (100\%) become transgenic after GFP infiltration into the core of sperm cell. Further explanation is displayed on Figure 2.
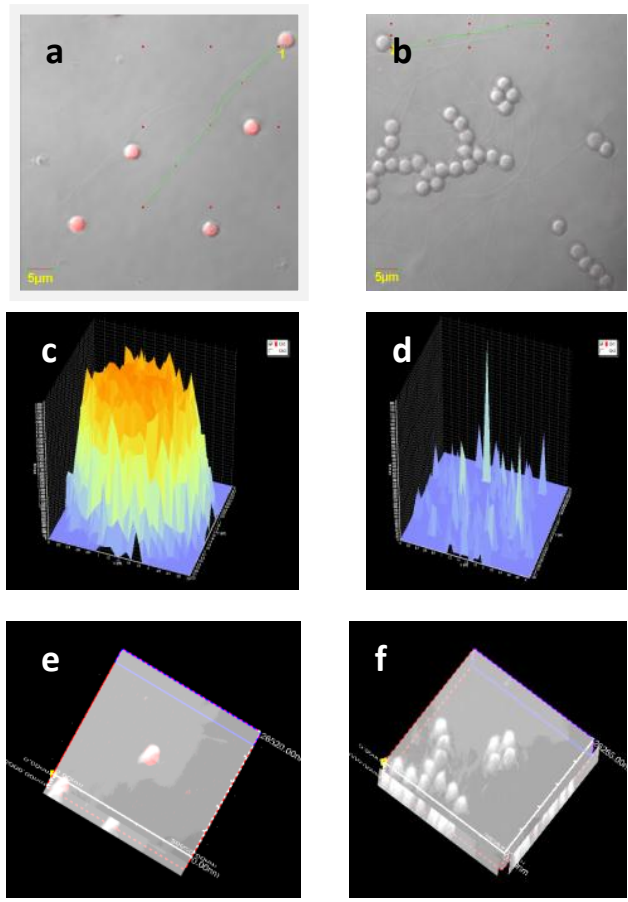

Figure 2. Observation on Carp Fish Sperm by Convocal Microscope. (a) Treatment sperm $\left(A_{1} B_{2}\right)$ with hrGFP that infiltrates the core has fluorescence intensity of 3700 arbitary; (b) Control sperm without hrGFP but with PI pigmentation at fluorescence intensity of 700 arbitary (autofluoresence); (c) Treatment sperm with PI at fluorescence intensity of 3700 arbitary; (d) Control sperm with $\mathrm{PI}$ at fluoresence intensity of 700 arbitary; (e) The 3-dimension display treatment sperm; (f). The 3-dimension presentation of control sperm.

Based on the result of observation with convocal microscope, as shown in Figure 2 above, there is different pigmentation intensity of Propidium lodide (PI) at treatment and control sperms. The Figure $2 \mathrm{e}$ and $2 \mathrm{c}$ displays the interaction of GFP and Carp Fish sperm. Regarding to the observation on fluorescence, it is shown that hrGFP at concentration $30 \mathrm{ng} . \mu \mathrm{L}$ $\left(A_{1} B_{2}\right)$ has infiltrated the core (Figure 2a, 2c, and 2e) at fluorescence intensity of 3700 arbitary. The intensity rate of control sperm is only 700 arbitary (Figures 2b, 2d, and 2f). Fluorescence phenomenon is also observed at control sperm (Figure $2 \mathrm{~b}$ and $2 \mathrm{~d}$ ) as shown by $\mathrm{PI}$ fluorescence in sperm. It does not mean that control sperm is containing GFP but this fluorescence derives from auto-fluorescence which fluorescents on sperm surface. Auto-fluorescence can be detected also in embryo or larva. It is because auto-fluorescence is natural fluorescence (usually seen in the living tissue culture) and mostly consisting of flavins and porphyrins and also plant such as chlorophyll [8]. The control (without electric shocking) have found that has produced shadow with low fluorescence. It may be caused by the combination of 69 auto-fluorescence units which can the background of fluorescence linkage on the surface [9].

The slicing that was analyzed by convocal microscope has shown that the construction of sperm cut in center part has indicated the infiltration of hrGFP into the core (Figure $\mathrm{c} 1$ ), and this infiltration is signed by bright orange color. Orange color is the pigmentation of sperm, or the effect derived from the mix between hrGFP (green) and PI (red). The brighter orange of the sperm is the greater infiltration of hrGFP into the core.

\section{hrGFP Fluorescence Rate at Treatment Sperm}

The observation of hrGFP intensity may determine fluorescence rate on sperm in every treatment. Besides, the interaction of GFP and sperm can be understood by ensuring whether fluorescence intensity rate of hrGFP (arbitary) is high or low. Based on the observation of fluorescence intensity rate, we found that the highest intensity rate on sperm is achieved at hrGFP concentration of 30 ng. $\mu \mathrm{L}$ (Treatment $A_{1} B_{3}$ ) with fluorescence intensity of 1050 arbitary. It is followed by concentration of 60 ng. $\mu \mathrm{L}^{-1}$ (Treatment $\mathrm{A}_{1} \mathrm{~B}_{2}$ ) with fluorescence intensity of 740 arbitary. The concentration of 90 $\mathrm{ng} . \mu \mathrm{L}$ corresponds with fluorescence intensity of 120 arbitary. Figure 3 described this arrangement.

In relative with the result of observation over sperm under convocal microscope, the lowest intensity is found at treatment with $90 \mathrm{ng} . \mathrm{\mu L}^{-1}$ $\left(A_{1} B_{3}\right)$, precisely at 120 arbitary. However, fluorescence rate of treatment sperm is higher than of control sperm that reaches only 90 arbitary (Fig. 4). Result of observation then suggests that fluorescence rate of hrGFP in treatment sperm is the lowest (120 arbitary), but it was still higher than fluorescence from control 
sperm (90 arbitary) because fluorescence of control sperm is also influenced by autofluorescence.

The luminescence of control sperm is derived from auto-fluorescent. The presence of natural fluorescence surface bonding in sperm cells with natural luminescence can be found among living tissue cultures or event plants, such as chlorophyll. Auto-fluorescent cells are staying within mitochondria and lysosome. Autofluorescent within cells are often dominated by pyridine nucleotides (NAD $(\mathrm{P}) \mathrm{H})$ and oxidized flavins (FMN, FAD). Both are potential to be the indicators of cellular metabolism [8].
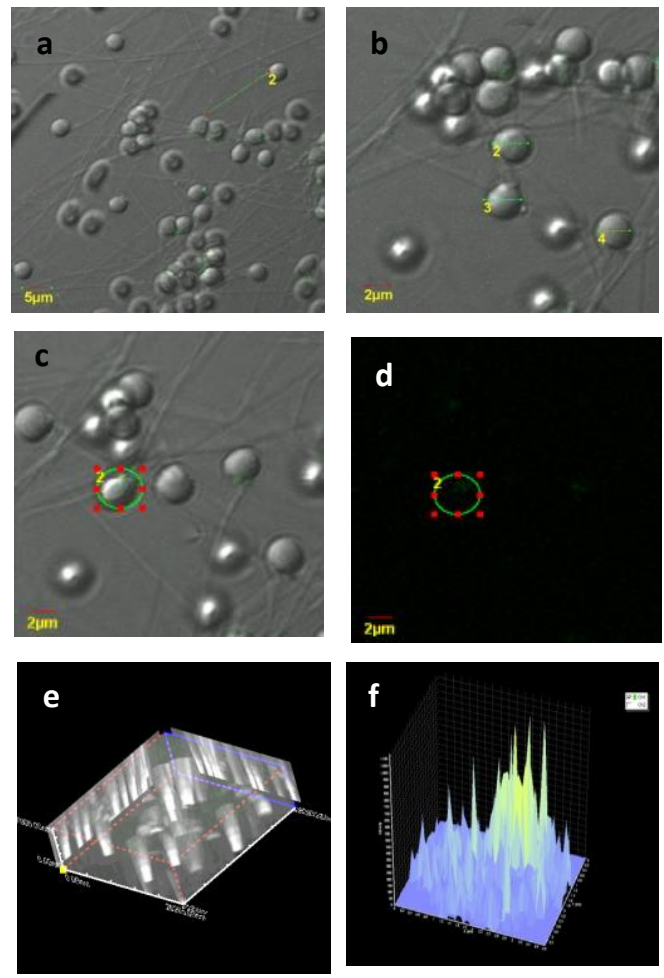

Figure 3. Carp Fish sperm at treatment of highest fluorescence intensity $\left(A_{1} B_{3}\right)(a)$. The display of sperm on SI screen with magnificence of 2400 times (b). The display of sperm on DIC screen with magnificence of 4800 times (c). The display on SI screen with magnificence of 4800 times (d). The display of hrGFP fluoresence in sperm on Fluorescence Screen (e). The display of sperm on screen based on 3-dimension reconstruction (f). Fluorescence intensity of Propidium lodide in Carp Fish sperm is 1050 arbitary.

\section{hrGFP Fluorescence in Carp Fish Embryo}

Result of observation also indicates that embryo is fluorescent in the highest intensity at treatment concentration of $30 \mathrm{ng} \cdot \mathrm{LL}^{-1}$ with fluorescence intensity of 4000 arbitary
(Treatment $A_{1} B_{1}$ ), and this rate is followed by intensity from concentration $60 \mathrm{ng} . \mathrm{\mu L}^{-1}$ with 3950 arbitary (Treatment $A_{1} B_{2}$ ). The lowest fluorescence intensity is obtained from concentration 90 ng. $\mu L^{-1}$ (Treatment $A_{1} B_{3}$ ) with fluorescence intensity of 2250 arbitary. Further detail is shown by the following figure 4 .

Whether luminescence intensity of GFP is high or low depends on several factors such as: DNA concentration and electric field force. Electrophoration does not directly influence embryonic development [10]. Electrophoration affects sperm motility [11]. This motility concerns with the number of embryos that survive until juvenile stage [12]. The efficiency of embryo transfer by the electrophorated sperm is relying on voltage and shock length. Exogenous DNA molecules may still adhere with sperm and can be carried over into oocyte during fertilization [13]. The electrophorated sperm can transport exogenous DNA more efficiently, and it is still carried over into salmon embryo [14].
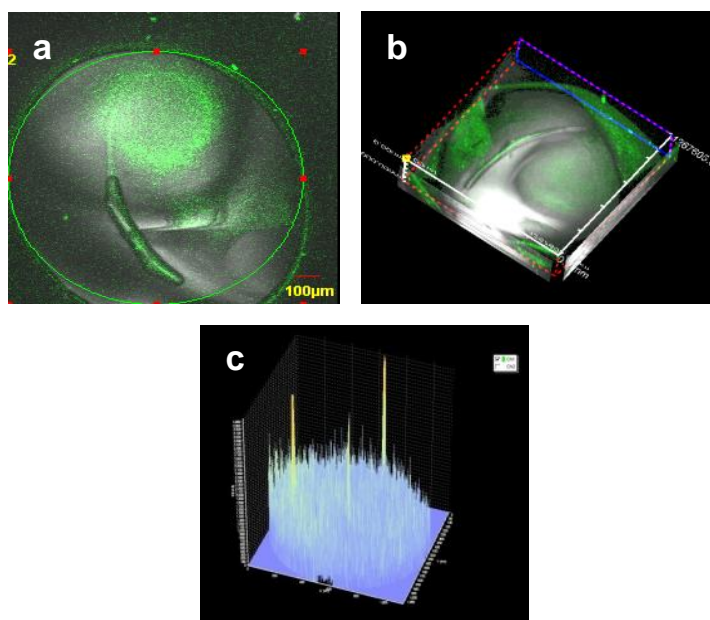

Figure 4. The highest of hrGFP fluorescence in Carp Fish embryo (Treatment $A_{1} B_{1}$ ) in 100 times magnification (a). The display on SI screen (b). The display on screen based on 3-dimension (c).

The lowest fluorescence intensity of hrGFP in the electroporated sperm is still higher than control sperm. Such phenomenon is consistent to fluorescence rate found in transgenic embryo of Catfish and Nilam Fish [3]. Faqih has found that GFP fluorescence rate of Catfish and Nilam Fish id different to each other despite similar hour age. GFP fluorescence intensity depends on several factors such as DNA concentration and electric voltage.

In the embryo produced from the electroporated sperm with hrGFP, the lowest fluorescence of embryo is found at hrGFP 
concentration of $90 \mathrm{ng} \cdot \mathrm{LL}^{-1}$ (Treatment $\mathrm{A}_{1} \mathrm{~B}_{3}$ ) with fluorescence intensity of 2250 arbitary. However, this lowest fluorescence was still higher compared to control sperm which only reaches 900 arbitary. Low fluorescence is possibly caused by the increase and development of embryonic tissue of Carp Fish and also linked to the distributional pattern of hrGFP expression (fluorescence) in Carp Fish embryo. hrGFP fluorescence distributional pattern in Catfish embryo is relatively spread throughout body part of embryo although the intensity is low. hrGFP fluorescence pattern in Nilam Fish embryo is lacking of evenly distribution [3].

\section{hrGFP Fluorescence in Carp Fish Larva}

In pursuance of the observation result of hrGFP fluorescence in Carp Fish larva that hatches already, it is indicated that hrGFP fluorescence at concentration $30 \mathrm{ng} \cdot \mathrm{\mu L}^{-1}$ (Treatment $A_{1} B_{1}$ ) can be explained as following. Fluorescence intensity of tail part of Carp Fish is 4000 arbitary, abdomen part is 3800 arbitary and head part is 3600 arbitary. At concentration 90 ng. $\mu \mathrm{L}$ (Treatment $\mathrm{A}_{1} \mathrm{~B}_{3}$ ), fluorescence intensity rate of the tail is 3700 arbitary (Fig. 5), the abdomen is 3950 arbitary (Fig.6), and the head is 3800 arbitary (Fig. 7).
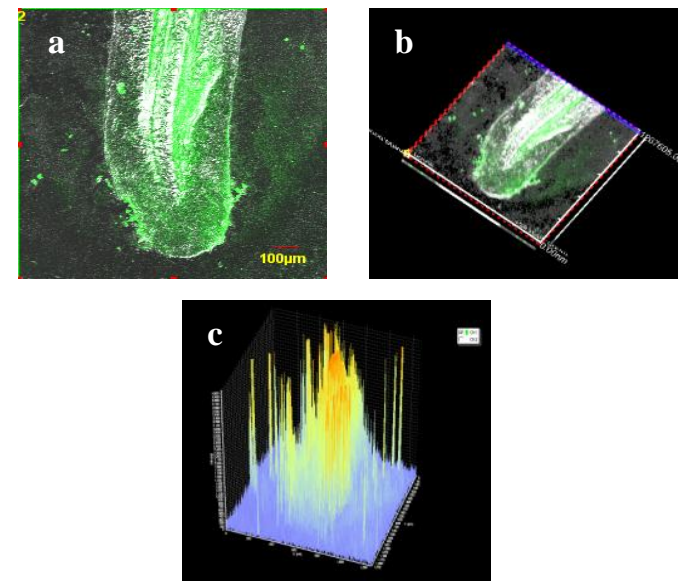

Figure 5. The highest hrGFP fluorescence in tail of Carp Fish larva (Treatment $A_{1} B_{1}$ ) at 100 times magnification (a). The display of hrGFP fluoresence in tail of Carp Fish larva on SI screen (b). The display of hrGFP in tail of Carp Fish larva on screen based on 3-D reconstruction (c). hrGFP fluorescence intensity rate in tail of Carp Fish is 4000 arbitary.

By considering the figures above, it can be said that the highest hrGFP fluorescence rate is found in tail part (4000 arbitary), followed by abdomen (3800 arbitary), and head (3900 arbitary). This rate is discovered at concentration $30 \mathrm{ng} / \mu \mathrm{l}$. hrGFP fluorescence rate in tail part is higher than other parts of the body. Based on data of observation result, the lowest GFP fluorescence rate in treatment (1450 arbitary for tail, 900 arbitary for abdomen, and 1300 arbitary for head) is still higher than fluorescence rate of larva of control Carp Fish (600 arbitary).
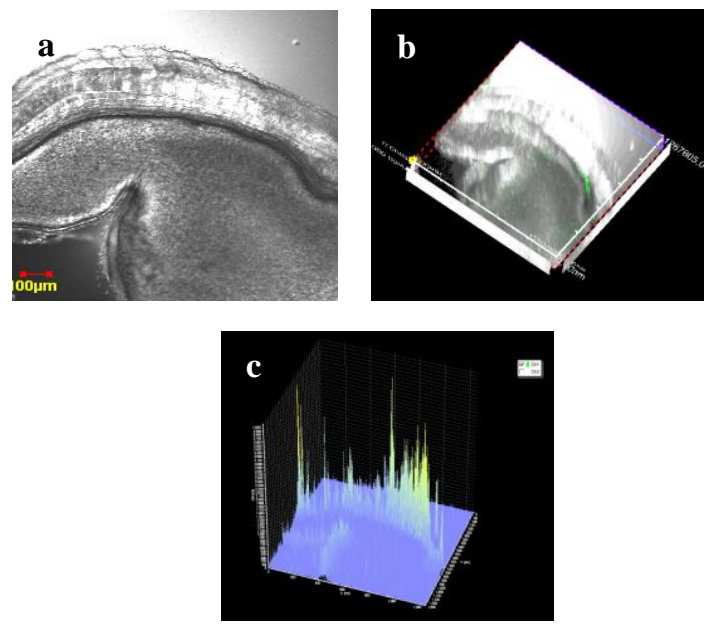

Figure 6. The highest hrGFP fluorescence in abdomen of Carp Fish larva (Treatment $A_{1} B_{1}$ ) at 100 times magnification (a). The display on SI screen (b). The display on screen based on 3-D reconstruction (c). hrGFP fluorescence intensity in abdomen of Carp Fish larva is 3800 arbitary.
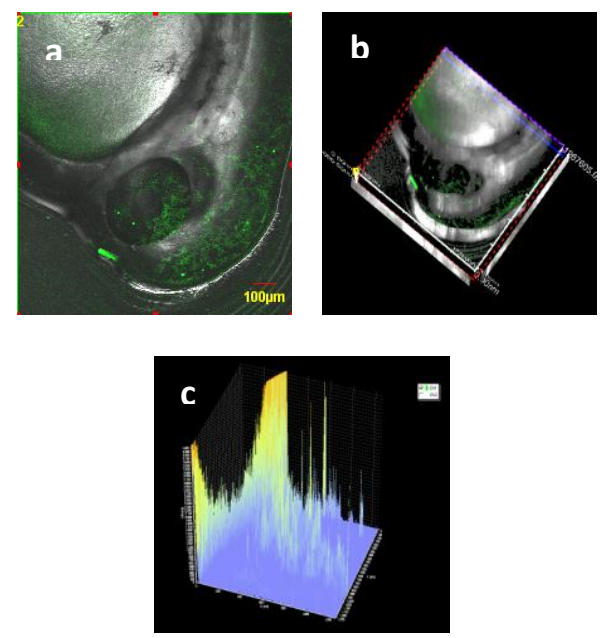

Figure 7. The highest hrGFP fluorescence in head of Carp Fish larva (Treatment $A_{1} B_{1}$ ) at 100 times magnification with fluorescence intensity of 3900 arbitary (a). The display on SI screen (b). The display on screen based on 3-D reconstruction (c). hrGFP fluorescence intensity in head of Carp Fish larva is 3900 arbitary.

Green Luminescence (GFP) is relatively strong and evenly spread in larva head of gold fish. GFP 
intensity in tail part is 4000 arbitary. This intensity level is still higher than GFP intensity on head and stomach parts of gold fish. High level of GFP in tail part is estimated as caused by the greater quantity of the successfully transferred GFP gene copies.

The transferred gene construction is integrated successfully with host genome and then, it begins the replication into multiple numbers. Therefore, the accumulated GFP can exude strong luminescence. This ability is attributed to the role of beta actine promoter in Medaka Fish where the construction of fish gene has included some characters in which the elements have different activities such as constitutive, ubiquitous and housekeeping [15].

The emergence of fluorescence is relatively strong because there is a fluorescence produced by the activity of two photoprotein, respectively aequorin and Green Fluorescent Protein (GFP). Both substances are isolated from sea jellyfish. Its molecular character is unique because calcium is linked with photoprotein aequorin in such way that blue light is produced while jellyfish produces green light. Green light emanated from GFP is produced by the activity of energy released by aequorin [16].

\section{Spermatozoa Quality}

The quality of the electroporated sperm can be explained as following. The quality of control sperm was $70 \%$ while treatment sperm is $30-$ $50 \%$. The viability of treatment sperm is $40-60 \%$ whereas viability of control sperm is $70 \%$. Therefore, the quality of both sperms is relatively good [3].

\section{CONCLUSION}

Based on the result of observation over GFP fluorescence intensity from sperm to larva, it was shown that GFP is very effective as gene reporter. The highest GFP fluorescence intensity was found at treatment with GFP concentration $30 \mathrm{ng} \cdot \mathrm{LL}^{-1}$. The quality of sperm after GFP electroporation was relatively good at concentration $30 \mathrm{ng} \cdot \mathrm{\mu L}^{-1}$.

To produce the expected effectiveness rate of trans-genesis against Carp Fish, it is suggested to use electric voltage of 30 Volt. $\mathrm{cm}^{-1}$, DNA concentration of $30 \mathrm{ng} \cdot \mathrm{\mu L}^{-1}$, pulse number of 4 times, and pulse length of $1 \mathrm{~ms}$ because these parameters are proved as more effective to produce higher successful rate of gene transfer and also more reliable to obtain better degree of fertilization and hatching compared to treatment with GFP concentration 60 and 90 ng. $\mathrm{LL}^{-1}$.

\section{REFERENCES}

[1] Kang, H.J., G. Yoshizaki, O. Homma, C.A. Strusmann, F. Takashima. 1999. Effect of osmotic differential on the effeciency of gene transfer by electroporation of fish spermatozoa. Aquaculture. 173. 297-307.

[2] Alimuddin, M.H., F. Ath-thar, L.I. Purwanti, O Carman. 2009. Promoter $\beta$-actin ikan Medaka (Oryzias latipes) dapat digunakan untuk membuat ikan Lele dan ikan Mas transgenik. Jurnal Akuakultur Indonesia. 6(1). 65-77.

[3] Faqih, A.R. 2011. Studi rekayasa genetik melalui elektroporasi sperma dalam pembuatan ikan transgenik air tawar. PhD Thesis. Graduate. Faculty of Agriculture. University of Brawijaya. Malang

[4] Beaumont, A.R., K. Hoare. 2003. Biotechnology and genetics in fisheries and aquaculture. School of Ocean Sciences. University of Wales. Bangor, UK.

[5] Sciamanna, I., L. Barberi, A. Martire, C. Pittoggi, R. Beraldi, R. Giordano, A.R. Magnano, C. Hogdson, C. Spadafora. 2003. Sperm endogenous reverse transcriptase as mediator of new genetic information. Biochem. Biophys. Res. Commun. 312. 10391046.

[6] Horan, R., R. Powell, J.M. Bird, F. Gannon, J.A. Houghton. 1992. Effects of electropermeabilization on the association of foreign DNA with pig sperm. Arch. Androl. 28. 105114.

[7] Houdebine, L.M. 1997. TransgeniC animals: generation and use. CRC Press. Boca Raton.

[8] Anderson, J.B., C. Sternberg, L.K. Poulsen, S.P. Bjorn, M. Givskov, S. Molin. 1998. New unstable variants of green fluorescent protein for studies of transient gene expression in bacteria. Appl. Environ. Microbiol. 64. 2240-2246.

[9] Prausnitz, M.R., S.B. Lau, C.D. Milano, S. Conner, R. Langer, J.C. Weaver. 1993. A quantitative study of electroporation showing a plateau in net molecular transport. Biophys. J. 65. 414-422.

[10] Squires, E.J. 1998. Status of spermmediated delivery methods for gene transfer. ABI Publishing. Cambridge University Press. New York.

[11] Rieth, A., F. Pothier, M.A. Sirard. 2000. Electroporation of bovine spermatozoa to 
carry DNA containing highly repetitive sequences into oocytes and detection of homologous recombination events. Mol. Reprod. Dev. 57. 338-345.

[12] Sin, F.Y.T, S.P. Walker, J.E. Symonds, I.L. Sin. 2008. Sperm mediated gene transfer in Chinook Salmon. Aquaculture. 117. 57-69.

[13] Smith K, Spadafora C. 2005. Spermmediated gene transfer: applications and implications. Bio Essays. 27. 551-562.

[14] Sin, F.Y.T. 2001. Gene transfer technology for Salmon. In: Milton, F., N. Rachakonda (Eds). Recent Advances in Marine Biotechnology: Molecular Genetics of Marine Organism. Science Publisher. USA. 10. 327-347.

[15] Volckaert, F.A., B.A. Hellemans, P. Galbuzera, F. Oliver. 1994. Replication expression and fate foreign DNA during embryonic and larva development of the African Catfish Clarias Gariepinus. Mol. Mar. Biol. Biotech. 3 (2). 57-69.

[16] Cubitt, A.B., R. Heim, S.R. Adams, A.E. Boyd, L.A. Gross, R.Y. Tsien. 1995. Understanding, improving and using green fluorescent Proteins. Trends Biochem. Sci. 20. 448-455. 